\title{
The demise of aprotinin: Our share of the blame
}

Thoralf M. Sundt, MD

From the Division of Cardiovascular Surgery, Mayo Clinic, Rochester, Minn.

Received for publication Feb 3, 2008; accepted for publication Feb 4, 2008.

Address for reprints: Thoralf M. Sundt, MD, Division of Cardiovascular Surgery, Mayo Clinica and Foundation, 200 First St, SW, Rochester, MN 55905 (E-mail: johnson. barbara4@mayo.edu).

J Thorac Cardiovasc Surg 2008;135:729-31 0022-5223/\$34.00

Copyright $\odot 2008$ by The American Association for Thoracic Surgery

doi:10.1016/j.jtcvs.2008.02.003

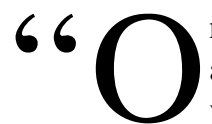
n November 5, 2007, after consultation with various health authorities around the world, Bayer announced that it would temporarily suspend worldwide marketing of Trasylol (aprotinin injection) until final results from the BART [Blood Conservation using Antifibrinolytics: A Randomized Trial in High-Risk Cardiac Surgery Patients] trial are compiled, received and evaluated. Shipments of Trasylol from Bayer distribution centers were halted that day." Many received the news with a combination of frustration at the prospect of losing access to a remarkably effective drug; others seemed quietly to celebrate that the company "finally got what it deserves," a feeling generated by the high cost of the medication and marketing tactics. Likely, to some degree, all of us felt a bit disturbed that the government was reaching down into our practices and passing judgment on a drug the risks and benefits of which we were surely in the best position to evaluate. Shouldn't we be able to sort this out on our own? How could the tables have turned so quickly, and who is responsible for the demise of this agent? Is it the company's fault or the government's fault, or do we share in the blame? How did we lose control of this matter?

Aprotinin has been in clinical use for well over a decade, with an enormous literature behind it. Indeed, a PubMed search today (January 30, 2008) with "Aprotinin" yields 7028 references. But the drug has received particular attention in the last several years after 2 large retrospective studies raised concerns about its safety, reporting an increased risk of death among individuals receiving the medication. ${ }^{2,3}$ More concerning, however, has been the preliminary analysis from the BART trial, a large, multicenter, prospective, randomized clinical study being conducted under the auspices of the Ottawa Health Institute at 25 Canadian medical centers. This study proposed to test the hypothesis that aprotinin was superior to 2 other antifibrinolytic agents, tranexamic acid and aminocaproic acid, in reducing the incidence of massive bleeding with cardiac surgery. ${ }^{4}$ Although the results of the study have not yet been released, the Data Safety Monitoring Board of the BART study informed the US Food and Drug Administration in October 2007 that it had stopped enrolling patients in the aprotinin treatment arm of the study because of "increased risk for death compared to two other antifibrinolytic drugs used in the study." Pharmaceutical Corporation suspended global marketing of the drug. Given the litigious nature of our society, this likely represents the death knell for this medication. A quick Internet search for the term "aprotinin" immediately brings up a number of sponsored links for legal firms offering assistance to those who might have experienced "Trasylol-related injury."

Aprotinin is certainly a remarkable drug. Its clinical efficacy in decreasing bleeding after cardiopulmonary bypass surgery is immediately apparent to anyone who has used it. As such, it speaks directly to the souls of cardiac surgeons and anesthesiologists who have spent countless hours in the operating room after a complex case trying just to "stop the bleeding." And yet concerns about the safety of the drug were raised early on. Indeed, my own first presentation at a thoracic surgical meeting and first publication in the thoracic surgical literature concerned the risks of intravascular thrombosis and renal dysfunction with aprotinin. ${ }^{6}$ Our observations were not unique, nor were our concerns. ${ }^{7,8}$ There quickly followed, however, a large number of subsequent studies supporting the safety of the drug. ${ }^{9-11}$ Aprotinin was rapidly integrated into practice; indeed, one of the most notable things about the drug is how quickly this integration occurred. Not only was it thought to be safe, but its virtues seemed quickly to 
expand, including reductions in pulmonary dysfunction, ${ }^{12}$ stroke, ${ }^{13}$ and even cognitive dysfunction. ${ }^{14}$ There seemed no downside at all to its use once the savings from reduced blood transfusions were shown to counterbalance the cost of the drug, ${ }^{15}$ but perhaps most notable was the remarkable intensity of opinion held among discussants of the subject. It was as if the drug has as powerful an effect on the individual administering the drug as the subject receiving the drug.

This is not a joking matter, however, because aprotinin is an important drug despite its risks, and we are worse off without it in our arsenal. Excessive bleeding continues to be a source of significant morbidity and mortality among high-risk individuals, and even those skeptics among us with concerns about adverse side effects of the drug must admit to using it on occasion. From a practical standpoint, however, this is no longer an option for any of us. How could this have happened? Could it have been our collective denial of the risks and accordingly its promiscuous use in both lowrisk and high-risk patients that is at the root of its withdrawal from the marketplace? How can we reconcile the differences between the reported studies, and how can we understand our own interpretations of the data? Well-performed studies seemed to demonstrate aprotinin to be one of the few riskfree interventions in cardiovascular surgery. Did we really believe that a drug with such an impressive effect had no downsides at all? Many of the findings now being presented are not new. Risks of renal dysfunction and intravascular clotting were identified more than a decade ago. Did the manufacturer indeed withhold information from us and from the US Food and Drug Administration (http://www.nytimes. com/2006/09/30/health/30fda.html)? Did they fool us, or did we fool ourselves?

Thomas Gilovich has addressed the question of cognitive determinants of our beliefs in his book, How we know what isn't so: The fallibility of human reason in everyday life. ${ }^{16}$ Gilovich addresses the characteristics of human perception and misperception that influence our understanding of events around us. Examining popular but mistaken assumptions, he argues that our reasoning is so often faulty because of what are at their roots self-serving beliefs: our use of incomplete, ambiguous, or inconsistent data and a natural human tendency to seek out "hypothesis-confirming evidence" and to "see what we expect to see." Once we have formed a belief, it is "human nature" to accept information consistent with those beliefs at face value. Many of these concepts are familiar to us. What is perhaps less intuitive is the common misconception that we simply overlook contradictory evidence. But surely this was not the case with aprotinin given the enormous literature on the subject. We examined the risks seriously and scientifically, didn't we?

The aprotinin storyline follows a familiar pattern. Literally hundreds of analyses and clinical studies, mostly retrospective, have been performed on aprotinin. We have debated the risks extensively and passionately. In fact, Gilovich ${ }^{16}$ might argue that this is exactly the point. In fact, he suggests that we do not overlook contradictory evidence at all; rather, we scrutinize it more critically than those data confirming our opinions. This bias, if you will, derives from fundamental cognitive function critical to our everyday life. We could not possibly live productively if we critically examined everything around us equally. It is only those matters that seem "out of place" that draw our focused attention and consideration.

Our "clinical experience" is profoundly affected by these basic cognitive characteristics. We remember the remarkable cases, especially those that went badly, and forget the ones that go smoothly and uneventfully. We scrutinize those events that seem to violate our beliefs in everyday practice, as well as in the scientific literature. On the other hand, we tend to recall events confirming our expectations with greater clarity than those that are contradictory. An instance of remarkable hemostasis in a patient known to be at high risk for bleeding is recognized as a success for aprotinin. Postoperative renal dysfunction in the same patient, with a baseline risk for such a complication, might be viewed as a nonevent: just what is to be expected when one takes on "big cases."

Is there something sinister in our attention to confirmatory evidence? No, it is merely a property of human psychology. The important observation is that we must first be aware of this tendency and then take extra efforts to guard against being misled. Confirmatory evidence is easier to deal with cognitively. This is particularly true if outcomes differ according to hedonic (or emotional) consequences. Motivational determinants affect our cognition by subtly affecting the evidence that we demand and the criticisms that we apply. As for bleeding versus renal dysfunction, rationally we are equally concerned with both types of morbidities. However, we witness bleeding standing at the operating table or the patient's bedside hour by hour, whereas renal failure frequently evolves gradually and less dramatically. When we are subconsciously invested in the answer, it turns the question from "Can I believe this?" to "Must I believe this?" The burden of evidence shifts from "supportive" for confirmatory evidence to "compelling" for contradictory evidence.

What is our safeguard against adherence to erroneous beliefs? It is careful adherence to the scientific enterprise itself that demands that outcomes be specified and specified at the front end of any study. This is a critical strength of prospectively randomized studies. Although it might be a source of tremendous frustration to clinicians as they argue with statisticians over the outcome of trials and apparent associations that were not specified during that trial's design, our adherence to these principles of scientific investigation are critical if we are to keep from fooling ourselves. Once those studies have been performed, we must be cautious about the application of the findings to broader clinical practice. Such an approach might even have preserved the availability of an unquestionably useful but potentially harmful drug. 


\section{References}

1. Available at: http://www.trasylol.com/Trasylol_01_04_08-2.pdf. Accessed March 7, 2008

2. Mangano DT, Miao Y, Vuylsteke A, et al. Mortality associated with aprotinin during 5 years following coronary artery bypass graft surgery. JAMA. 2007;297:471-9.

3. Mangano DT, Tudor IC, Dietzel C. The risk associated with aprotinin in cardiac surgery. $N$ Engl J Med. 2006;354:353-65.

4. Available at: http://www.ohri.ca/programs/clinical_epidemiology/ thrombosis_group/studies/bart.asp. Accessed March 7, 2008.

5. Available at: http://www.fda.gov/CDER/previous_news2007.htm. Accessed March 7, 2008

6. Sundt TM 3rd, Kouchoukos NT, Saffitz JE, et al. Renal dysfunction and intravascular coagulation with aprotinin and hypothermic circulatory arrest. Ann Thorac Surg. 1993;55:1418-24.

7. Cosgrove DM 3rd, Heric B, Lytle BW, et al. Aprotinin therapy for reoperative myocardial revascularization: a placebo-controlled study. Ann Thorac Surg. 1992;54:1031-8.

8. Westaby S, Katsumata T. Aprotinin and vein graft occlusion-the controversy continues. J Thorac Cardiovasc Surg. 1998;116:731-3.

9. Lemmer JH Jr, Stanford W, Bonney SL, et al. Aprotinin for coronary bypass operations: efficacy, safety, and influence on early saphenous vein graft patency. A multicenter, randomized, double-blind, placebocontrolled study. J Thorac Cardiovasc Surg. 1994;107:543-53.

10. Taggart DP, Djapardy V, Naik M, Davies A. A randomized trial of aprotinin (Trasylol) on blood loss, blood product requirement, and myocardial injury in total arterial grafting. J Thorac Cardiovasc Surg. 2003;126:1087-94.

11. Alderman EL, Levy JH, Rich JB, et al. Analyses of coronary graft patency after aprotinin use: results from the International Multicenter Aprotinin Graft Patency Experience (IMAGE) trial. $J$ Thorac Cardiovasc Surg. 1998;116:716-30.

12. Rahman A, Ustunda B, Burma O, et al. Does aprotinin reduce lung reperfusion damage after cardiopulmonary bypass? Eur J Cardiothorac Surg. 2000;18:583-8.

13. Frumento RJ, O'Malley CM, Bennett-Guerrero E. Stroke after cardiac surgery: a retrospective analysis of the effect of aprotinin dosing regimens. Ann Thorac Surg. 2003;75:479-84.

14. Harmon DC, Ghori KG, Eustace NP, et al. Aprotinin decreases the incidence of cognitive deficit following $\mathrm{CABG}$ and cardiopulmonary bypass: a pilot randomized controlled study. Can J Anaesth. 2004;51:1002-9.

15. Smith PK, Datta SK, Muhlbaier LH, et al. Cost analysis of aprotinin for coronary artery bypass patients: analysis of the randomized trials. Ann Thorac Surg. 2004;77:635-43.

16. Gilovich T. How we know what isn't so: the fallibility of human reason in everyday life. New York: The Free Press; 1991.

\section{JTCVS On-Line Manuscript Submission and Review}

The Journal of Thoracic and Cardiovascular Surgery requires authors and reviewers to submit all new and revised manuscripts and reviews via Editorial Manager. Point your browser to http://jtcvs.editorialmanager.com, log in as author or reviewer (as appropriate), and follow the instructions provided.

To retrieve your username and password, click "Forget your password?" on the Editorial Manager log-in page.

If you have questions or experience problems uploading your manuscript or review, please contact the editorial office:

Telephone: 215-762-1854

E-mail: jtcvs@drexelmed.edu 